\title{
ESTADO Y REFORMA ENERGÉTICA EN MÉXICO
}

\author{
Marco A. Merchand ${ }^{1}$
}

Fecha de recepción: 12 de febrero de 2015. Fecha de aceptación: 2 de junio de 2015.

\begin{abstract}
RESUMEN
Este ensayo analiza, cómo las reformas en el sector energético emprendidas por el gobierno de Enrique Peña Nieto (2012-2018) representan la culminación de un Estado, que no está interesado en salvaguardar el patrimonio territorial. Es el propio Estado, que aplica la acumulación por despojo para beneficio de los particulares, sobre todo de las transnacionales que ganan licitaciones en megaproyectos energéticos -termoeléctricas(petroleras, mineras, telecomunicaciones, etcétera). El Estado favorece el despliegue de la acumulación del capital a favor de la lógica de la cadena de valor global en las actividades más diversas: energéticas, agropecuarias; inmobiliarias e incluso turísticas.
\end{abstract}

Palabras clave: México, Estado, reforma energética, privatización, inversión extranjera. Clasificación JEL: L32, N76, O13, Q43, Q48.

\section{The State and Energy Reform in Mexico}

\begin{abstract}
This article examines how the energy sector reforms rolled out by the Enrique Peña Nieto (2012-2018) administration represent the culminating act of a State disinterested in safeguarding Mexico's territorial patrimony. It is the State itself that is imposing accumulation by dispossession to the benefit of the few, especially multinational companies that win the tenders for energy megaprojects -such as thermal power plants- or projects in oil, mining, telecommunications, etc. The State promotes capital accumulation that favors the global value chain in a wide range of activities: energy, agriculture and livestock, real estate, and even tourism.
\end{abstract}

Key Words: Mexico, State, energy reform, privatization, foreign investment.

1 Universidad de Guadalajara, México. Correo electrónico: merchandrojas@yahoo.com.mx 


\section{ÉTAT ET RÉFORME ÉNERGÉTIQUE AU MEXIQUE \\ Résumé}

Cet essai analyse comment les réformes dans le secteur énergétique entreprises par le gouvernement d'Enrique Peńa Nieto (2012-2018) constituent le point culminant d'un État qui ne se soucie pas de sauvegarder le patrimoine territorial. C'est l'État luimême qui fomente l'accumulation de capital privé via la spoliation au profit d'intérêts particuliers, surtout ceux des entreprises transnationales qui gagnent des appels d'offre pour de mégaprojets visant l'exploitation et la fourniture d'énergies (centrales thermoélectriques, exploitation pétrolière ou minière, télécommunications, etcetera). L'État favorise l'essor de l'accumulation du capital en appliquant la logique de la chaine globale de valeur aux activités les plus diverses : l'énergie, le secteur agricole, l'immobilier et même le tourisme.

Mots clés: Mexique, État, réforme énergétique, privatisation, investissement étranger.

\section{ESTADO E REFORMA ENERGÉTICA NO MÉXICO}

\section{Resumo}

Este ensaio analisa como as reformas no setor energético empreendidas pelo governo de Enrique Peña Nieto (2012-2018) representam a culminação de um Estado que não está interessado em salvaguardar o patrimônio territorial. É o próprio Estado que aplica a acumulação por despossessão para beneficio de particulares, sobretudo das transnacionais que ganham licitaçóes em mega-projetos energéticos - termoelétricas, petroleiras, mineiras telecomunicaçóes e etcétera -. O Estado favorece a arrancada da acumulação do capital a favor da lógica da cadeia de valor global nas atividades mais diversas: energéticas; agropecuárias; imobiliárias e inclusive turísticas.

Palavras-chave: México, Estado, reforma energética, privatização, investimento estrangeiro.

政府与墨西哥能源改革

本文分析, 由恩里克 - 佩尼亚 - 涅托（2012-2018）总统发起的能源改 革, 如何代表了一个对捍卫领土财富丝毫不感兴趣的政府的巅峰之作。政 府通过剥夺而积累财富, 为少数群体牟利, 尤其是在大型能源一热电项目 中（石油、矿产、电信等等）竞标成功的跨国公司。政府在各项生产活动 中支持促进全球价值链的资本积累: 能源、农牧业、房地产甚至旅游业。

关键词：墨西哥, 政府, 能源改革, 初级化, 外资 


\section{INTRODUCCIÓN}

A lo largo de este trabajo, se analiza cómo el Estado allana el camino a todo tipo de inversiones a través de las privatizaciones de los activos públicos que legalmente están a su resguardo, con el estilo de desarrollo neoliberal se instrumenta la venta de estos activos (privatizaciones) y se empieza a operar de esta forma; una devaluación masiva de sus activos (agua, petróleo, minas telecomunicaciones, transporte, sistema de provisión social, etcétera). Para alcanzar este objetivo general, la exposición se ordena a partir de plantear el alcance epistémico y la conjetura que sustenta este trabajo, también se explica cómo se concretiza el concepto de acumulación por desposesión en México y por último, se explica la transcionalización a lo que va estar sujeto el sector enérgico, después de las reformas implementadas en dicho sector.

\section{PLANTEAMIENTO METODOLÓGICO DEL OBJETO DE ESTUDIO}

Respecto al planteamiento metodológico sobre el estado del arte objeto de estudio, se plantea una visión epistémica que sustenta la premisa de que al implementarse reformas en el sector energético; éstas tienen el objetivo sustancial de reconfigurar el territorio a partir de las necesidades del capital transnacional, a través de espacios nacionales y/o locales.

La hipótesis que sustenta este análisis, es que el Estado opera a favor de los capitales extranjeros, mercantilizando los bienes naturales, es decir, cosificándolos y transformándolos en propiedad privada para poder apropiarse de ellos. El Estado instrumenta la acumulación por desposesión (despojo), siendo éste un ejercicio de poder que se ha expresado en el devenir histórico del capitalismo, aunque esta acumulación por despojo cobra fuerza ideológica a partir del modelo neoliberal y representa, si no la única forma, sí la más importante actualmente para sostener o incrementar la acumulación de capital en la geografía global a través de apropiarse de los espacios locales y/o regionales.

Estos espacios locales y/regionales se privatizan y son acotados ahora por intereses extranjeros (inversiones transnacionales), esto es en gran medida porque ya el Estado no es soberano (el Estado ya no toma sus propias decisiones para defender el territorio nacional de intereses extranjeros); el Estado ahora sólo es una instancia promotora de dichas inversiones extranjeras (Garay et al., 2013). Estos espacios desgobernados que se caracterizan por tener un Estado ya "no soberano" y que decide no regular y/o acotar a las actividades 
extractivas de las transnacionales, caracteriza la etapa actual de la globalización neoliberal (Garay, 1999).

Esta práctica de la globalización neoliberal ocurre cuando los espacios de un territorio nacional, local y regional de un país, se privatizan y están cada vez más expuestos a externalidades negativas por parte de capitales extranjeros.

En síntesis, un rasgo distintivo de globalización o de la economía política global, se expresa en un proceso de titularización de bienes agrícolas y recursos naturales en los mercados mundiales de capitales. Este concepto de un mercado mundial de capitales, adquiere relevancia a partir de una multiplicidad de formas de dominación, como es a través de la adquisición masiva de tierras; el licenciamiento extensivo del subsuelo para la explotación de recursos naturales no renovables; la implantación de modalidades para la mercantilización del uso de la tierra, como el Derecho Real de Superficie (DRS). La generalidad que adquiere este mercado de capitales, es el acaparamiento del uso del suelo y del subsuelo y/o en la propiedad de tierras, en países en desarrollo por parte de capitales extranjeros (Garay, 2013).

El que alecciona bien lo explicado anteriormente es David Harvey (2014) en su reciente libro: Las diecisiete contradicciones y el fin del capitalismo, donde explica y ejemplifica lo acontecido en 2008 con la crisis financiera y dice, que el: valor de uso y valor de cambio (con el crash de la vivienda en Estados Unidos, millones de personas fueron desposeídas de sus casas -valor de uso- por la especulación, o sea el elevado valor de cambio). David Harvey completa lo explicado más arriba, los poderes y prácticas del Estado han estado cada vez más dirigidos a satisfacer las demandas de las empresas y los accionistas, a menudo a expensas de los ciudadanos. Esto implica un fuerte apoyo del Estado a la creación de un buen clima de negocios, favorable al capital. El resultado es, en muchos casos, que a los Estados les puede estar yendo muy bien, mientras que a sus poblaciones les va muy mal.

Asimismo, habría que explicar que dentro de las primeras contradicciones funcionales analizadas por Harvey, es la contradicción entre propiedad privada y Estado capitalista, la que nos interesa destacar. Harvey explica que esta contradicción se crea una diferencia entre lo que se llaman derechos de usufructo (que corresponden al uso activo) y derechos de propiedad exclusiva permanente. Esa diferencia ha sido a menudo fuente de confusión, en particular en toda la historia del colonialismo. Las poblaciones indígenas funcionan con frecuencia sobre la base del derecho de usufructo de la tierra, por ejemplo: como sucede en el caso de la agricultura itinerante. Las potencias coloniales impusieron casi siempre derechos de propiedad excluyente, lo que fue y sigue siendo origen de muchos conflictos. Las poblaciones que se movían de un 
lado a otro siguiendo a sus ganados o desplazándose de tierras improductivas a otras nuevas y más fértiles, se encontraban de repente impedidas de utilizar tierras que habían considerado tradicionalmente a su disposición, porque ahora estaban cercadas y rodeadas de alambre de espino por alguien que las poseía perpetua y absolutamente, aunque no las utilizara.

Además, la imposición de estos derechos de propiedad privada depende de la existencia de poderes estatales y de sistemas jurídico-legales (usualmente acoplados con los de recaudación impositiva en forma monetaria) que codifican, definen y hacen valer las obligaciones contractuales que corresponden al derecho de propiedad privada y a los derechos, de los sujetos jurídicos individuales, es más, existe una contundente evidencia de que el poder coercitivo del Estado desempeñó un importante papel en la apertura de espacios en los que pudiera florecer el capital mucho antes de que se hicieran dominantes los regímenes de propiedad privada.

El mismo Harvey ańade a su comentario, que actualmente la erradicación de los derechos de usufructo y los odiosos procesos de cercamiento de los bienes comunes han hecho posible el dominio de un sistema de propiedad privada individual irrestricta, respaldado este dominio, por el poder del Estado. Como garante de esos derechos de propiedad privada se apela al Estado, con su monopolio del uso legítimo de la fuerza y la violencia, para evitar o reprimir cualquier transgresión del régimen de los derechos de propiedad privada individualizada. El Estado capitalista debe usar el monopolio adquirido sobre los medios de violencia para proteger y preservar ese régimen, tal como se articula en el funcionamiento "libre" de los mercados.

Por cuestión de espacio, no podemos proseguir la discusión sobre la importancia del Estado en el modelo neoliberal, habiendo una serie de importantes autores y perspectivas teóricas ${ }^{2}$ sobre el papel que asume el Estado, aquí se destaca la asumida por Robert Jessop (2008) quien también refleja el cambio experimentado por el Estado; del Estado de bienestar (welfare) al Estado de trabajo (workfare), donde el aparato organizador y legitimador y coercitivo estatal se pone al servicio ya no de la inclusión social y del aumento de la calidad de vida de los ciudadanos, sino de la competitividad de las empresas en la arena internacional o como decía Ralph Miliband (1978); el Estado es un clásicos del Estado (dígase Weber o Marx), ni por supuesto, tampoco en los desarrollados posteriormente, ya sean en la tradición pluralista o marxista. Lo que existe son diferentes aproximaciones, cada una con diferentes propósitos y diferentes contextos históricos, que de forma eventualmente iluminada se complementan unos con otros. 
instrumento de la clase dominante, aunque es una formulación compleja que no debe ser leída en forma lineal.

En el siguiente apartado, se específica más el concepto de acumulación por desposesión (despojo) que es un elemento clave por parte del Estado para que los recursos naturales sean apropiados por el capital, tanto nacional, como extranjero.

\section{LA ACUMULACIÓN POR DESPOSESIÓN (DESPOJO)}

Antes de analizar con mayor profundidad, la acumulación por desposesión, también llamada acumulación por despojo y/o acumulación originaria se hace indispensable remitirse a los autores (De Angelis, Bonefeld, Composto) que ubican el concepto a partir del planteamiento de nuevos cercamientos ${ }^{3} \mathrm{y}$ que incluso, el propio Harvey hace referencia en sus libros.

Por cuestiones de tiempo y espacio no se entrará a reconstruir los debates y las polémicas generadas dentro de la tradición marxista sobre el concepto de acumulación por desposesión empleado por Harvey (2007), no es la intención detenernos en este caso, en toda la espesura teórica de estos debates y conceptos. La intención es sólo referenciar brevemente el concepto de acumulación originaria que se ilustra a partir de la entrevista que hace Claudia Composto y Mina Lorena a John Holloway. La pregunta trazada por Composto y Lorena recobra el planteo de Massimo De Angelis, quien sostiene:

Que la acumulación originaria es un proceso inherente y permanente incluso en las sociedades del capitalismo maduro, que se expresa mediante la continuación de la separación violenta entre las personas y, no solamente sus medios de producción, sino sus condiciones de vida en general, lo que podríamos denominar "lo común"; y sostiene que, por ejemplo, el neoliberalismo es una expresión actual de la acumulación originaria, en tanto ha avanzado sobre formas comunitarias, territorios, relaciones sociales que estaban por fuera de la órbita del mercado como resultado de luchas sociales históricas" (Composto y Lorena, 2012).

En síntesis, para Holloway es más útil pensar el despojo en términos de una estrategia para superar la crisis de la explotación, y no como otra forma de acumulación. Si decimos que el capital depende, no solamente de la ex- 
plotación del trabajo, sino de la explotación cada vez más acelerada, cada vez más intensa del trabajo. La postura de Holloway coincide con la expuesta por (Massimo De Angelis, 2012) quien sostiene que el capital despliega procesos de acumulación originaria ex novo que profundizan la privatización y mercantilización de lo común, toda vez que el trabajo se erige como un obstáculo para su reproducción y genera rigideces en la dinámica de la acumulación. De Angelis sostiene que la acumulación primitiva no puede ser reducida a un acontecimiento histórico pasado, sino que se encuentra necesariamente presente en los sistemas capitalistas "maduros" como proceso inherente que, dada la naturaleza conflictiva de las relaciones capitalistas, asume un carácter continuo.

En la misma tesitura, el propio W. Bonefeld (2012) detalla más el concepto, se ha argumentado que la acumulación primitiva es una acumulación reproducida en forma constante, ya sea en términos de renovada separación de nuevas poblaciones de sus medios de producción y subsistencia, o en términos de la reproducción de la relación salarial en las relaciones "establecidas" del capital. La primera busca llevar nuevos trabajadores bajo control del capital y la segunda, contenerlos allí como categorías sociales "liberadas" de sus condiciones.

Es precisamente a partir de la reconstrucción y/o renovación de la acumulación originaria; la importancia que tiene el autor italiano De Angelis de replantear la acumulación del capital como una política de "nuevos cercamientos" y privatización de bienes comunes acontecida en las últimas dos décadas tanto en vastas regiones de Europa Occidental, como en casi la totalidad de América Latina.

Este rasgo de privatización que cobra fuerza con el neoliberalismo y que explica muy bien Harvey en su libro Nuevo Imperialismo, se expresan continuas privatizaciones de espacios comunales, activos públicos, bosques, lagos y montes a lo largo y ancho de nuestro continente, deben leerse como parte de una amplia estrategia de acumulación capitalista, basada en mecanismos predatorios que buscan convertir estas instancias vitales y bienes comunes en productos con alto nivel de rentabilidad. Y es precisamente a partir de aquí, que llegamos el punto nodal de este trabajo que es analizar cómo la alta rentabilidad está a cargo de las transnacionales, siempre y cuando sean afianzadas con el apoyo irrestricto de lo que se ha llamado "Estado nacional de competencia" que, en tanto entidad responsable de crear el espacio para la acumulación, se convierte en socio de la desapropiación, pero en una posición asimétrica de sesión frente a los intereses transnacionales. 
Un ejemplo que se acomoda perfectamente, es a lo explicado por Composto (2012) que recalca cómo otorgar garantía a la continuidad de la reproducción ampliada por parte de los países periféricos; es el de la ofensiva extractivista que implicó la creciente integración subordinada de las economías de la periferia al circuito de la gran producción capitalista global expresado en el nuevo carácter de la dependencia y los procesos de recolonización característicos de las últimas décadas (Seoane, 2012).

Es en los países de América Latina donde se instaura un proceso que se denomina "ofensiva extractivista", definido como un perene ciclo de profundo y acelerado avance de la expropiación, mercantilización y depredación de los bienes comunes naturales de la región, en tanto estrategia del capital frente a la crisis global de acumulación que suscribe actualmente al sistema (Seoane, 2012).

Ahora, por lo que respecta a la acumulación por desposesión (Harvey, 2004) concepto central que se utiliza en este trabajo; dicha acumulación por despojo cobra fuerza ideológica a partir del modelo neoliberal y representa, si no la única forma, sí la más importante actualmente para sostener o incrementar la acumulación de capital en la geografía global (lograr el establishment del sistema bancario y de las grandes corporaciones y centros de poder-BM-FMI у ВСЕ $\left.{ }^{4}\right)$.

El rasgo económico-político que definiría, dicha acumulación por desposesión, es que su instrumentación para llevarse a cabo necesita obligatoriamente que el Estado y los dueños de capital (productivo, comercial, financiero) tengan el interés común "contubernio" de que los espacios receptores sirvan para que el capital incremente su capital; lo que se logra sólo expropiando el derecho del trabajador de vivir dignamente con un empleo bien remunerado. En palabras de David Harvey (2007) quien posibilita la acumulación por desposesión es la liberación de un conjunto de activos, incluida la fuerza de trabajo a un coste muy bajo y en algunos casos, nulo.

Harvey (2007) ha ayudado a comprender la importancia del concepto de acumulación de capital que se hace necesario estudiarlo sobre todo cuando el capitalismo ha experimentado una transición entre el viejo modelo de acumulación a uno nuevo. Harvey caracteriza el fordismo como el viejo modelo (la cadena de montaje de producción en masa, la organización política de masas y las intervenciones del Estado de bienestar) y, la acumulación flexible (el nuevo modelo) que se caracteriza en general por la búsqueda de mercados

4 BCE (Banco Central Europeo). 
especializados, opera la descentralización unida a la dispersión espacial de la producción y, una retirada del Estado-nación de las políticas intervencionistas propiciando la liberalización y privatización de los activos del Estado.

Es también, el Estado que gracias a su monopolio sobre el uso de la violencia y su definición de la legalidad, desempeña un papel crucial tanto en el apoyo como en la promoción de estos procesos. Ante este listado de mecanismos, se debe añadir la extracción de rentas de las patentes y los derechos de propiedad intelectual, y la disminución o la anulación de varias formas de derechos de propiedad comunes (como son las pensiones del Estado, las vacaciones retribuidas, y el acceso a la educación y a la atención sanitaria).

En el mismo tenor que lo explica Harvey (2007), la competencia entre los diferentes territorios (Estados, regiones, o ciudades) por poseer el mejor modelo de desarrollo económico o el "mejor clima para los negocios", era una cuestión relativamente insignificante en la década de los cincuenta y los sesenta. Sin embargo, la contienda entre territorios y/o países por atraer capitales (Estados-nación que incentivan que promueven la entrada de capitales -IED directa e indirecta-) se intensifica después de los años setenta con la puesta en marcha de un modelo neoliberal que ha propiciado a la larga un desarrollo geográfico mundial más desigual en términos de un proceso de acumulación por desposesión y que tiene su equivalente con el de la apropiación del espacio $y$, esta apropiación puede ser ejecutada por un imperialismo formal e informal dependiendo de intensidad de la dominación; sea violenta o disimulada (Wallerstein, 1988).

También se completa dicha explicación con el argumento:

Hay que destacar la importancia que cobra y se le exige a los Estados-nación, favorecer el despliegue de la acumulación del capital en la lógica de la cadena de valor global en las actividades turísticas, agrícolas, mientras e industriales. En otras palabras, como lo explica Harvey (2004) la soberanía Estatal sobre la circulación de mercancías y capitales es entregada en una actitud servicial al mercado global. El quid del asunto, para David Harvey se encuentra en la soluciones espacio-temporales, porque generan demanda, tanto de inversión como de bienes de consumo en otros lugares (ejemplo: la actividad turística). Incluso extendiendo más el concepto sobre el despliegue de la acumulación de capital, el petróleo y otros recursos geoestratégicos de México, incluida la tierra como mercancía, están incluidos entre los objetivos neocoloniales de Washington y el capital corporativo trasnacional, plasmados en la Alianza para la Seguridad y la Prosperidad de América del Norte (Merchand, 2012b: 37-38). 
Se ha dicho de una y otra forma que la acumulación por desposesión no puede implementarse sin el apoyo irrestricto del Estado y que éste ha sido un actor central en los cuatro aspectos que cubre la acumulación por desposesión (privatización y mercantilización, financiarización, gestión y manipulación de la crisis y redistribuciones de la crisis). Siendo el Estado empleador de la violencia y hacedor de la legalidad, es evidente que todo proceso económico que implique manejo de recursos económicos y/o activos financieros pasa por su tamiz para cubrir el despojo jurídicamente, pues hay que recordar que el Estado es un poder de clase que se expresa en flexibilizar las leyes (desregulación) para que las distintas denominaciones del capital se adueñen de los recursos productivos y financieros de sus territorios y, así permitir que el capital aproveche las condiciones desiguales en la economía espacial en términos de distintas dotaciones de recursos diferenciales en el ámbito nacional, regional y local.

Cabe insistir, que los elementos de análisis que integran el concepto de acumulación por desposesión deberían de abarcar en primera instancia, analizar la noción de espacio geográfico, como una relación de fuerzas políticas entre la tensión a nivel mundial y nacional. La perspectiva asumida, supone que el actual escenario mundial refleja la relación dialéctica de dos lógicas de poder: la territorial y la capitalista. ${ }^{5}$ La relación entre estas dos lógicas debe entenderse de modo conflictivo -y con frecuencia contradictorio- más que de forma funcional o unilateral, en cuanto al Estado y el capital estos siguen conformando y articulando relaciones de conveniencia económica-política que empaten los intereses de las dos lógicas descritas.

Luego entonces, se considera la composición de esas dos lógicas o vectores aludidos (la territorial y la de capital), en términos de poder. Por un lado, se tiene el interés de Estados Unidos -en cuanto Estado-nación que detenta una política de poder Estado-imperial-como proyecto político específico de amplio alcance, propio de agentes cuyo poder se basa en el control sobre un territorio frente al resto de los Estados-nación del continente, asegurándose al mismo tiempo este Estado imperial de una importante porción geográfica del mundo de cara a las disputas con otros bloques de poder de acuerdo a la división del poder mundial.

El Estado para garantizar la reproducción del capital global crea un espacio jurídico para las corporaciones transnacionales por encima de la soberanía 
estatal, como es el caso de las transnacionales petroleras que se instalaran en territorio mexicano.

\section{LA REFORMA ENERGÉTICA FAVORECE A LA INVERSIÓN EXTRANJERA}

La pregunta que hay que hacerse de inició, es por qué el Estado actúa de la manera que lo hace, una de la razones es que desde los ańos setenta, y hasta el día de hoy, la economía de los países en desarrollo han sido dominadas por el enfoque neoclásico impuesto por los neoliberales, ${ }^{6}$ donde los operadores mundiales de tal modelo son los dos organismos financieros (Fмг у вм) que sustentan el liderazgo de Estados Unidos. El condicionamiento que ejercen estos organismos internacionales sobre el accionar de la política económica de los países, es con el cometido de afianzar y reproducir exitosamente los capitales productivos, comerciales y de servicios de carácter global en sus economías nacionales. De ahí, que uno los principales desafíos de la política económica es que toda intervención de política garanticé a toda costa otorgar garantías al capital productivo y financiero.

Esto es, la mayoría de los gobiernos de América Latina, con diferente énfasis, insisten en insertarse en la economía global, lo cual inevitablemente exige que se eliminen las regulaciones, trabas y costos en el comercio de bienes y flujos de capitales. Este proceso de globalización lleva al dilema de redefinir el papel de Estado-nación, aplicando medidas para atraer inversiones y promover exportaciones. En las últimas décadas, a partir del inicio del neoliberalismo y el auge de la globalización, América Latina registra un proceso de "desestatalización" del Estado, por el cual es despojado de sus atribuciones principales, es así como el Estado ha sido progresivamente despojado de su función de gobernar. No sólo ha perdido su eficiencia gobernante, sino que también ha confundido y cambiado los modos de gobernar, y ha dejado de ser un organismo e instrumento de gobierno.

6

\footnotetext{
Los neoliberales, que dominan el escenario económico y político actual sostienen, en principio, que el "Estado" ha de tener una actuación mínima y reducirse a mantener un marco propicio para la actuación del sector privado. Afirman que de esta manera el sector privado tendrá un contexto de mayor estabilidad, más beneficios y mayores estímulos para su actuación. De acuerdo con estos planteamientos los neoliberales sólo consideran adecuada la intervención para mantener "la ley y el orden", que quiere decir principalmente el garantizar la propiedad privada y apoyar los negocios. Concluyen, que tanto el gasto público debe ser lo menor posible, así como los impuestos que tengan que pagar las personas y los beneficios de las empresas.
} 
Por ejemplo para la atracción de los capitales internacionales, se reducen los estándares, laborales, se otorgan excepciones fiscales y sobretodo se brinda estabilidad macroeconómica (tipo de cambio estable, tasas de interés altas respecto a la internacional) que brinden condiciones seguras al capital productivo y financiero.

Respecto el caso de México y en relación al Estado capitalista neoliberal mexicano, éste puede ser ejemplificado y caracterizado por las recomendaciones que emite el Tribunal Permanente de los Pueblos (Tpp, 2014). ${ }^{7}$

El Estado mexicano, como muchos otros Estados en América Latina, ha implementado desde mediados de los años ochenta, políticas públicas y programas de gobierno centrados en todo tipo de despojos de los bienes públicos y de los bienes comunes de los pueblos. El objetivo de este despojo y/o por acumulación por desposesión que aplica el Estado ha consistido en implementar un modelo extractivista, no apoyado sólo en la explotación del petróleo, sino en un extractitivismo energético que incluye gas convencional, gas shale, viento, energía solar y, por supuesto, también minero e incluso hidrológico, estos recursos naturales están actualmente controlados por empresas petroleras y gasíferas, sobre todo de capital estadounidense, y en el caso de minería, de capital canadiense.

Para John Saxe (2002) se han instrumentado mecanismos militares y financieros por parte de Estados Unidos de América para garantizar el despojo de los recursos estratégicos, no sólo de México, sino de la gran mayoría de los países latinoamericanos. Esta descripción muestra la condición secular de México, primero como colonia y después como país periférico y, que nos coloca históricamente bajo presión geopolítica y económica. Se registra históricamente, una transferencia al exterior de una buena cantidad de riquezas expresadas en mecanismos financieros a través de permanentes pagos de deudas internacionales, también de mecanismos comerciales de intercambio desigual y de una explotación desmedida de recursos naturales por parte de empresas extranjeras.

Esta forma de operar del Estado mexicano de concesionar y/o vender recursos naturales que pertenecen a la nación a intereses espurios (empresas

El Tribunal Permanente de los Pueblos (TPP), fundado en 1979, es heredero del primer tribunal creado por Bertrand Russell para juzgar los crímenes cometidos por el gobierno estadounidense en la guerra contra Vietnam, y del tribunal que se organizó con Julio Cortázar para juzgar a la dictadura militar argentina. Ahora, el Tpp ha sesionado en México bajo el título Libre Comercio, Violencia, Impunidad y Derechos de los Pueblos en México, en cuyo marco se han realizado diferentes audiencias frente a jueces internacionales y nacionales determinados por el propio TPP (2014). 
transnacionales, que sólo explotan irracionalmente los recursos naturales), significa invertir el orden institucional que se había construido con base en la Constitución Política mexicana de 1917. Esta actitud distorsionada empleada por el Estado neoliberal, en el que usa sus atribuciones y poderes para garantizar posiciones de privilegios, no sólo a una oligarquía nacional, sino directamente a una oligarquía internacional, principalmente estadounidense.

En otras palabras este Estado, que no cumple con deberes de defender la soberanía nacional y permite que las riquezas nacionales queden en manos monopólicas de un cerrado grupo de empresas transnacionales, se le califica como una conducta de "desviación de poder económico" ${ }^{8}$ Para concretizar, está "desviación de poder económico" el Estado emplea sus instituciones legitimadoras a través de instrumentación de leyes y normas (reformas energéticas), con el fin de beneficiar a poderosos interés particulares, certificado así, el despojo de los recursos naturales que pertenecen originariamente al pueblo.

En México, algunas situaciones y casos que claramente ilustran la "desviación de poder", son:

- La instrumentación de las instituciones públicas para favorecer intereses de las élites económicas y políticas a través de múltiples simulaciones jurídicas.

- El desmantelamiento de la Constitución Política mexicana de 1917 a través de contrarreformas neoliberales durante los últimos cinco sexenios.

Esta "desviación de poder", se muestra ya en el sexenio de Carlos Salinas (1988-1994), quien envía una reforma para modificar el artículo 27 de la Constitución ${ }^{9}$ y que sin duda representa la reforma social más importante de

"En México, la desviación de poder es una figura desconocida. En un par de resoluciones recientes, la Suprema Corte de Justicia reconoce la figura como una hipótesis plausible. La primera Sala de la Corte habla de la desviación y exceso de poder como un uso distorsionado de atribuciones discrecionales, uso que por ello, se convierte en arbitrariedad. En España la figura está prevista expresamente en la legislación desde 1956. La nueva ley reguladora de la jurisdicción contenciosa administrativa número 29/1998 define la desviación de poder como el ejercicio de potestades administrativas para fines distintos de los figados en el ordenamiento jurídico" (трр 2014/15).

La reforma al artículo 27 y su ley agraria permiten el diseño de políticas públicas que buscan eliminar la propiedad social en los hechos. Como lo es el caso del Programa de Certificación de Derechos Ejidales y Titulación de Solares (Procede) el cual fomenta la mercantilización y privatización de las tierras de ejidos y comunidades que adoptan la figura jurídica de "dominio pleno". Modalidad que suprime el carácter "imprescriptible, inalienable e inembargable" de las tierras. Dominio pleno que se orienta a la fragmentación y titulación de manera individual de las tierras 
las leyes agrarias del país. Dicho cambio jurídico al artículo 27 constitucional, permite que bajo determinadas circunstancias, ocurra la compra-venta, el arrendamiento y otras concesiones de la tierra, algo que estaba prohibido en la legislación anterior. La privatización y la desnacionalización en el modelo neoliberal empieza operar con la entrega integral de recursos naturales estratégicos (partes importantes de la industria petrolera, electricidad, minería metálica, agua y biodiversidad), incluso de infraestructura estratégica (ferrocarriles, puertos marinos, líneas de cabotaje y áreas de navegación de altura, red satelital, etcétera).

Alejandro Nadal (2013) explica con apreciación justa lo acontecido, pues parece que la única tarea de los gobernantes consiste en imponer esquemas de dominación sobre las mayorías para beneficiar a unos cuantos. En contra de toda lógica económica y política se impuso al pueblo de México la decisión de entregar el sector energético a las empresas transnacionales que nunca ocultaron su apetito por los yacimientos de hidrocarburos en el espacio económico mexicano. Así que la reforma consiste en reabrir las puertas a las empresas que fueron expulsadas de esta industria en 1938. Aquí cabe otra adjetivitización, que hace William Robinson (2013), sobre el Estado que se adapta para manejar una economía liberalizada dominada por los intereses del capital transnacional. Es decir, en sus propias palabras, "la transnacionalización del capital se transnacionaliza sobre la base sobre la cual los funcionarios del Estado y la élite política realizan su producción". Sin embargo, esto no quiere decir que el capital ya no necesita al Estado para crear y mantener las condiciones necesarias para su expansión, sino más bien "el sistema de Estados nacionales, compuesto de unidades discretas interactuando entre sí, ha dejado de ser el principio organizador del desarrollo capitalista".

Esta regresión destruye componentes fundamentales del Estado mexicano tal y como emerge de la Revolución. El control sobre los recursos naturales había sido hasta ahora uno de los aspectos más importantes en la lucha por alcanzar independencia y desarrollo. Por eso seguía siendo uno de los principios esenciales en la Constitución Política de 1917. Y si los gobiernos que se fueron sucediendo a partir de los ańos ochenta abandonaron el proyecto de

\footnotetext{
y territorios comunales y fomenta su incorporación al mercado de tierras. Tierras que pueden ser vendidas, hipotecadas y embargadas, así como arrendadas a empresas, modificando las diversas estructuras espaciales históricas que han construido los indígenas y campesinos en sus tierras y territorios por un lado; así como la destrucción de las asambleas comunitarias, que son la institución social que rige y regula la vida al interior de los ejidos y comunidades como máximo órgano de autoridad. Ejidales y comunales que se tenía antes de la reforma de 1992.
} 
alcanzar el desarrollo económico, los preceptos constitucionales sobre control patrimonial de los recursos naturales no perdían validez y servían para recordar lo que podría ser el camino del desarrollo económico. Hoy esos preceptos han sido desfigurados y el retroceso histórico ha reemplazado a la promesa del desarrollo. Las mismas instituciones que en teoría debieran velar por los intereses nacionales son las que sirvieron para acelerar los trámites de la traición.

Desde el gobierno de Vicente Fox, el extractivismo energético se instrumenta a favor de la privatización y el otorgamiento del recurso petrolero y sus derivados a empresas transnacionales estadounidenses (Shell, Halliburton, Schulemberger). De acuerdo al artículo periodístico de Alfredo Jalife-Rahme (2014), ${ }^{10}$ las empresas estadounidenses han posicionado a las cuatro megapetroleras globales -Exxon Mobil, Chevron, Shell y BP- como las principales beneficiadas de la reforma energética, mediante la cual el "México neoliberal" se destraba de la explotación tanto de las aguas profundas del Golfo de México como del tóxico gas shale (gas esquisto/lutitas), ${ }^{11}$ que merece tratamiento especial por las serias consecuencias para disponibilidad de agua en zonas adyacentes a los sitios de extracción

El cuadro 1 refleja las medidas de apertura que se le otorga a una industria petrolera subcontratada.

En el gobierno de Enrique Peña Nieto con la reforma energética, ya aprobada, se pone en práctica la acumulación por despojo que se hace posible legalmente por las reformas constitucionales y de leyes secundarias en materia energética y que correspondieron a formas de dominación política, mediante un complejo proceso de presión-negociación-cooptación, o incluso represión, a los actores del campo. Como ya se explicó, la acumulación por despojo y/o

"Entre las 12 principales transnacionales menos éticas (¡supersic!) aparecen tres petroleras de Estados Unidos: Halliburton, Chevron y Occidental Petroleum. Exxon Mobil (449 mil millones de dólares en ingresos; tercer lugar del ranking de las 500 transnacionales más poderosas Fortune/ CNN): su enorme derrama (750 mil barriles) en Alaska en 1989 compite con BP en el Golfo de México por el mayor daño global al ambiente” (Alfredo Jalife-Rahme, 2014).

11

La producción de shale gas o gas natural de lutita en Estados Unidos ha sorprendido al mundo por su rápido desarrollo y repercusión en la disminución del precio del combustible y el aumento de reservas de hidrocarburos. Este desarrollo ha crecido junto con la oferta de petróleo y de condensados de gas natural. Se estima que Estados Unidos serían autosuficientes en petróleo y superavitarios en gas natural en menos de 30 años. El renovado impulso de los hidrocarburos no-convencionales empieza a ser visto como una revolución energética que dará nuevo dinamismo a la economía de ese país. Por su novedad, la evaluación completa de estos desarrollos confronta dificultades metodológicas, estadísticas y de conocimiento científico, tecnológico, social y económico. Las regiones de Estados Unidos y Canadá con yacimientos de shale gas comprobados son muchas. 


\begin{tabular}{|c|c|}
\hline Gobiernos neoliberales & Apertura de la industria petrolera \\
\hline $\begin{array}{l}\text { Gobierno de Vicente Fox } \\
(2000-2006)\end{array}$ & $\begin{array}{l}\text { Privatización integral de la industria del gas. Desmantelamiento del Instituto } \\
\text { Mexicano del Petróleo, centro estratégico de investigación científica y tecnología } \\
\text { vinculado a Petróleos Mexicanos. }\end{array}$ \\
\hline $\begin{array}{l}\text { Gobierno de Felipe Calderón } \\
\text { (2006-2012) }\end{array}$ & $\begin{array}{l}\text { Se permite a las transnacionales de Estados Unidos controlar (mediante contratos) } \\
\text { la extracción de yacimientos marítimos de las principales reservas de crudo en las } \\
\text { aguas del Golfo de México, al tiempo que se busca (en dos ocasiones: } 20 \text { de mayo } \\
\text { de } 2008 \text { y 2011) acelerar el proceso de privatización de la industria petroquímica } \\
\text { en manos del Estado. A finales del sexenio (mayo de 2012) se calcula que el } \\
80 \% \text { de la industria petrolera y el } 55 \% \text { de la industria eléctrica estaban ya en } \\
\text { manos privadas. }\end{array}$ \\
\hline $\begin{array}{l}\text { Gobierno de Enrique Peña Nieto } \\
(2012-2018)\end{array}$ & $\begin{array}{l}\text { El } 20 \text { de diciembre de } 2013 \text { se publicó en el Diario Oficial de la Federación (DOF), } \\
\text { las reformas y adiciones constitucionales en materia energética. Asimismo, el } \\
\text { pasado } 30 \text { de abril de } 2014 \text {, el C. Presidente de la República envió al Congreso de } \\
\text { la Unión un paquete con proyectos de Decreto que expiden, reforman, adicionan } \\
\text { y derogan diversas disposiciones de leyes secundarias que podrá ser discutido y } \\
\text { aprobado en un periodo extraordinario de sesiones en junio del presente año. En } \\
\text { materia de hidrocarburos, se modificaron los artículos } 27 \text { y } 28 \text { constitucionales } \\
\text { para permitir la participación de los sectores público y privado en las actividades de } \\
\text { la industria energética. Esta iniciativa propone un nuevo esquema sin precedentes } \\
\text { en el país, el cual busca trascender en todos los ámbitos. }\end{array}$ \\
\hline
\end{tabular}

Fuente: elaboración propia.

desposesión, incluye la mercantilización y privatización de la tierra y la expulsión forzosa de las poblaciones campesinas; la conversión de diversas formas de derechos de propiedad -común, colectiva, estatal, etcétera- en derechos de propiedad exclusivos; la supresión del derecho a los bienes comunes.

Cabe mencionar que una de las formas jurídicas de atentar contra la propiedad de las tierras y los territorios indígenas es la expropiación, un acto unilateral de la Administración Pública, Federal o Estatal, cuyo fin es privar a los propietarios, privados o sociales, del uso, goce, disfrute y disposición de sus bienes "por causa de utilidad pública".

La figura no es nueva. Concebida durante la época cardenista (1934-1940) para fortalecer el proyecto nacional, ahora sirve para fomentar el lucro individual en detrimento del bien común y de la propiedad social. La expropiación ha sido usada por el Estado mexicano para llevar a cabo grandes obras públicas que luego se entregan a los particulares para que las usufructúen, entre ellas, las presas hidroeléctricas (López, 2014a). 
Respecto al despojo de tierras privadas, sociales e incluso públicas en favor de las empresas extranjeras que llegarán al país a explotar el petróleo, está incluido en la ley de hidrocarburos (artículo 33) ${ }^{12}$ y se amplía en la ley de órganos reguladores coordinados en materia energética. Se establece que los contratos para exploración y extracción de hidrocarburos, para tender ductos, además de construir la infraestructura respectiva, se otorgarán conjuntamente con la respectiva declaración de utilidad pública de los predios en cuestión. ${ }^{13}$

Cabe citar el artículo de López Bárcenas (2014b) que refleja en forma similar lo postulado aquí, la reflexión del autor, nos explica que las reformas legales que se están consumando en el Congreso de la Unión para transformar profundamente el régimen de extracción del petróleo y el gas, así como la generación de energía eléctrica, representan una segunda desamortización de las tierras y los recursos naturales, similar a la que se vivió en el país en el siglo xIx, pero esta reforma energética va más allá. De acuerdo con el Diccionario de la Real Academia de la Lengua Española, desamortizar es "situar en estado de venta los bienes de manos muertas, mediante disposiciones legales".

El agravante de esta reforma de ley, es que los recursos no están en manos muertas, es decir, están improductivas, sino que estos recursos, han servido para generar bienestar a los mexicanos. El despojo de tierras se aplicará con toda seguridad a las comunidades agrarias, que son las que se van afectar más, pues son las que poseen en propiedad la mayor parte del territorio mexicano, lo mismo que los territorios de los pueblos indígenas, ${ }^{14}$ que son bajo los cuales se encuentran los bienes codiciados por el capital. Con las reformas se abre el camino para un uso discrecional de expropiar y de imponer modalidades a la propiedad; la diferencia es que estas medidas privatizadoras no están orientadas a favorecer el fortalecimiento de la nación y el cuidado de sus bienes, para que apuntalaran el bienestar de los mexicanos, ahora se usarán en beneficio de los particulares.

Diario Oficial de la Federación (2014). Ley de Hidrocarburos se reforman diversas disposiciones de la Ley de Inversión Extranjera.

Reforma Energética Resumen del proyecto de decreto que expide las leyes secundarias en materia de hidrocarburos. El presente resumen considera las iniciativas de leyes secundaria en materia energética, enviadas por el Ejecutivo Federal el pasado 30 de abril del presente año, al Congreso de la Unión, por lo que está sujeto a cambios que serán aprobados durante el mes de junio próximo (Zenteno, 2014). tipo. La intención de la reforma fue liberalizar el mercado de tierras con el objetivo de fomentar la penetración de relaciones capitalistas de producción. El ejidatario, ahora "liberado" de la tierra, se ve convertido en mano de obra barata. 
López Bárcenas (2014b), recalca que las medidas colaterales a la Ley Energética, en cuanto a expropiaciones, no restringirán la acción del capital, sino que este capital se utilizará para despojar a los campesinos y pueblos indígenas de sus propiedades en nombre de la nación, aunque todos sabemos que es para favorecer a los dueños del capital transnacional.

La Ley Energética se pondrá en práctica a través de las comisiones de la Reforma Nacional de Hidrocarburos y Reguladora de Energía, que son los órganos reguladores del sector energético, tendrán además la facultad, según el mismo artículo 33, de

promover los actos jurídicos que se requieran para hacer efectiva, la declaratoria de utilidad pública, siendo siempre estas actividades de interés social y de orden público, por lo que tendrán preferencia sobre cualquier otra que implique el aprovechamiento de la superficie del subsuelo de los terrenos, afectos a éstas. Estos órganos reguladores facilitarán el trabajo a las empresas extranjeras. "Ellas no tendrán que negociar nada, desde el Estado mexicano se harán las gestiones para que puedan disponer de los predios que requieran para hacer los negocios con el petróleo o la electricidad".

Este artículo 33 "abre la puerta a la expropiación de terrenos por supuesta utilidad pública, a afectaciones, incluso a reservas de la biosfera, esta disposición va más allá de la reforma energética aprobada en diciembre de 2014".

En síntesis, la Reforma de la Ley de Hidrocarburos y sus leyes secundarias permiten que empresas privadas, nacionales o extranjeras inviertan en México en la exploración y explotación de hidrocarburos: petróleo, gas y sus derivados. Desde la expropiación petrolera de 1938, estas actividades eran exclusivas del Estado. La manera en la que las empresas privadas podrán participar en la exploración y explotación de hidrocarburos será a través de la celebración de contratos con el Estado. Estos contratos podrán ser de licencia, de servicios y de utilidad o producción compartida, y serán asignados a través de licitaciones por la Comisión Nacional de Hidrocarburos ( $\mathrm{CNH}$ ), uno de los dos órganos reguladores del sector.

La misma Ley de Hidrocarburos contempla la posibilidad de que el área contractual otorgada a un particular abarque terrenos en poder de un propietario. En ese caso, para poder iniciar sus actividades el contratista tendrá que llegar a un acuerdo con el dueńo de la tierra, ya sea de compraventa o para permitir el uso por medio de las figuras de servidumbre legal, ocupación temporal o afectación superficial. 
La ley también abre la puerta a la explotación de gas de esquisto o shale, que se obtiene mediante una práctica conocida como fractura hidráulica o fracking que consiste en perforar la tierra e introducir agua y químicos a presión para sacar el hidrocarburo.

Sin embargo, la propia Alicia Bárcena Ibarra, secretaria general de la Comisión Económica para América Latina y el Caribe (Cepal), ${ }^{15}$ propuso que México no sólo mire el caso de Noruega para lograr mayor independencia en la explotación de su petróleo, sino que también considere los modelos de Bolivia y Ecuador, integrantes de la Alianza Bolivariana para los Pueblos de Nuestra América. Vale la pena ver con detalle las estrategias de Bolivia y Ecuador, que incluso cambiaron sus constituciones, renegociaron sus contratos con las empresas extranjeras y lograron convenios mucho más favorables a sus sociedades. En el caso de Noruega, se mantiene un fuerte pacto social. Eso es lo que debemos hacer, lo que nos puede dar la esperanza de que los recursos naturales van a estar al servicio de nuestra sociedad.

Cabe citar el caso de Bolivia (Petrich, 2014a), que se antojaría como un modelo a seguir por la forma como renegoció sus concesiones y contratos con las empresas transnacionales en las minas y el gas. En el gobierno de Bolivia del presidente Evo Morales, se aplicaron, dos procedimientos. En términos de la propiedad del gas, y petróleo en menor medida, bajo tierra o en el ducto, se nacionalizó todo. Ninguna empresa particular puede inscribir los recursos que encontró en subsuelo en la bolsa de valores como propios. Para las instalaciones y la maquinaria se firman contratos de servicios. En exploración, las empresas buscan gas y petróleo y si encuentran el recurso, éste pertenece al Estado. El gobierno, decide a quién y en cuánto se vende. Por la maquinaria, la tecnología y la mano de obra, se paga lo invertido y remuneramos con un porcentaje de ganancia entre 10 y $15 \%$ de la renta, el gobierno se queda con el resto. Como se ha visto, el caso de México va en sentido contrario, hacia la privatización y entrega a empresas extranjeras.

El resultado económico de estas nacionalizaciones de gas, hace que Bolivia, abandone su ancestral sitio entre los países más pobres de Sudamérica. Ahora, con el proceso de una política nacionalizadora de hidrocarburos y minas, Bolivia se sitúa entre las tres economías de mayor crecimiento en la región. El ańo próximo se espera un crecimiento arriba de $5 \%$, sustentado en su política de renacionalización de sus recursos naturales, principalmente gas y minería. 
En el caso de México, desde hace casi 30 años, el crecimiento promedio anual muestra un declive pronunciado que no sobrepasa el $2.3 \%$ durante más de 20 años, incluso de los países latinoamericanos, México es que el menos ha crecido. ${ }^{16} \mathrm{Si}$ esto le sumamos que en los últimos reportes oficiales preliminares del organismo subsidiario más importante de la empresa productiva de Estado, Pemex Exploración y Producción (PEP), revelan que en enero de 2015 la producción de crudo continuó con su desplome y ahora se ubica en un promedio diario de 2 millones 235 mil barriles por día, nivel similar al que tenía Petróleos Mexicanos (Pemex) hace 35 ańos. El volumen de 2 millones 235 mil barriles diarios extraídos en enero de 2015 se ubica en niveles de 1980-1981 y en términos reales podría incluso ser menor, porque la producción reportada es antes de mermas, movimiento de inventarios, traspasos y sustracción ilícita o robo del hidrocarburo.

Este desplome de la producción de petróleo se ve acompañado de un recorte presupuestal anunciado el 30 de enero de 2015 por la Secretaría de Hacienda y Crédito Público (sHCP) a la petrolera mexicana (Pemex) por 62 mil millones de pesos. ${ }^{17} \mathrm{La}$ caída en la producción, la baja en las cotizaciones del crudo ${ }^{18}$ y el recorte al gasto, tendrá implicaciones no sólo para la hacienda pública, sino para México en su conjunto. ¡El gobierno de Peña Nieto piensa revertir esta crisis con la llegada de inversiones en el sector energético a partir de las reformas implementadas, se logrará, sustentar un crecimiento económico incluyente para todos los mexicanos, aquí se ha sostenido que no!

Conviene tener presente que en junio pasado el Banco Mundial (вм), en su informe Perspectivas económicas mundiales pronosticó que el crecimiento de México no rebasaría 2.3\%. Un mes después, en julio el Fondo Monetario Internacional (FMI) también modificó a la baja su previsión de desarrollo para nuestro país y lo disminuyó a $2.4 \%$ frente al $3 \%$ calculado en el mes de abril. Y apenas a inicios de agosto, la Comisión Económica para América Latina y el Caribe (Cepal) determinó recortar de 3.0 a $2.5 \%$ su pronóstico de crecimiento de la economía mexicana para este 2014. Los pronósticos para 2015 de estos organismos no rebasan 3.5\% .

"El gobierno federal reconoció el 31 de enero de 2015, la necesidad de recurrir a un recorte en el gasto público por un monto de 124 mil millones de pesos, equivalente a $0.7 \%$ del producto interno bruto (PIB). La medida fue calificada por el secretario de Hacienda, Luis Videgaray Caso, como de carácter preventivo en reconocimiento a un cambio en el entorno financiero internacional y a la caída en los precios del petróleo" (González, 2015).

La mezcla de petróleo mexicano de exportación se cotizó en 91 dólares en enero de 2014, ya en los primeros de días febrero de 2015, el precio se desplomó a 40 dólares por barril, más del 100\% de caída, en estos primeros meses de año. El precio de la mezcla de petróleo mexicano de exportación, es la principal fuente de financiamiento del gasto público y se muestra una tendencia a su disminución que se ha mantenido. 
Las interrogantes, son ¿por qué México no crece? ¿Por qué la economía no asciende lo suficiente para satisfacer las necesidades de empleo y de bienestar de la mayoría de los mexicanos?

En el informe publicado en marzo de 2014 y realizado en conjunto por el Instituto Global McKinsey y la oficina de McKinsey en México (2014): "La historia de dos México's: el crecimiento y la prosperidad en una economía de dos velocidades", se analiza la problemática del crecimiento económico de nuestro país: hay dos México's, uno donde florece una economía moderna de alto crecimiento y el otro donde está instalada la economía tradicional de bajo rendimiento. Estos dos México's, se están moviendo en direcciones contrarias: mientras que en el sector moderno hay crecimiento y se puede competir a nivel internacional, en el tradicional con empresas pequeñas y medianas, algunas a menudo informales, la productividad se hunde.

\section{CONCLUSIONES}

Se ha dicho que la acumulación por desposesión y/o despojo no puede implementarse sin el apoyo irrestricto del Estado y que éste ha sido un actor central en los cuatro aspectos que cubre la acumulación por desposesión (privatización y mercantilización, financiarización, gestión y manipulación de la crisis y redistribuciones de la crisis). Siendo el Estado, empleador de la violencia y hacedor de la legalidad, es evidente que todo proceso económico que implique manejo de recursos económicos y/o activos financieros pasa por su tamiz para cubrir el despojo jurídicamente, pues hay que recordar que el Estado es un poder de clase que se expresa en flexibilizar las leyes (desregulación) para que las distintas denominaciones del capital (minero) se adueñen de los recursos productivos y financieros de sus territorios y, así permitir que el capital aproveche las condiciones desiguales en la economía espacial en términos de distintas dotaciones de recursos diferenciales en el ámbito nacional, regional y local.

Al cuestionamiento de la actividad de las empresas transnacionales en la explotación del patrimonio natural (recursos mineros, petroleros, turísticos, agrícolas, etcétera), habría que tomar en cuenta: por un lado, el daño ambiental que la actividad extractiva suele provocar en el entorno de sus operaciones, cuyas secuelas son difíciles de mitigar a corto y mediano plazo, además de afectar a las poblaciones cercanas y, por otro lado también, los nulos o pocos aportes de dichas transnacionales a los ingresos fiscales, vía pago de impuestos y otras regalías. Hay que plantearse, la necesidad de que las empresas paguen lo que corresponde por el derecho de extraer recursos naturales no renovables, teniendo en cuenta que existen abundantes recursos y buenas condiciones 
físicas para la explotación y/o su extracción, lo que abarata los costos de las compañías.

En este sentido, los procesos de sobreexplotación del entorno ambiental, castigan aún más a aquellos recursos no renovables como gas natural, petróleo, metales y piedras preciosas, que han configurado la base fundamental de las actividades extractivas generadoras de renta en enclaves económicos.

\section{BIBLIOGRAFÍA}

Bonefeld, Werner (2012), "La permanencia de la acumulación primitiva: fetichismo de la mercancía y constitución social”, Theomai 26, segundo semestre, Buenos Aires, Argentina.

Cepal (2014), Informe: Panorama Social de América Latina 2014.

Composto, Claudia (2012), "Acumulación por despojo y neoestractivismo en América Latina. Una reflexión crítica acerca del Estado y los movimientos socio-ambientales en el nuevo siglo", Astrolabi, núm. 8, http://revistas.unc. edu.ar/index.php/astrolabio

Composto, Claudia y Navarro Lorena (2012), "El despojo es una estrategia del capital para superar la crisis de la explotación”, entrevista con John Holloway, Theomai 26, segundo semestre, Buenos Aires, Argentina.

De Angelis, Massimo (2012), "Marx y la acumulación primitiva. El carácter continuo de los 'cercamientos capitalistas', Theomai 26, segundo semestre, Buenos Aires, Argentina.

Diario Oficial de la Federación (2014), Ley de Hidrocarburos y se reforman diversas disposiciones de la Ley de Inversión Extranjera, <http://www.dof. gob.mx/nota_detalle.php?codigo $=5355989 \&$ fecha $=11 / 08 / 2014>$

Garay, Luis (1999), Globalización y crisis. ¿Hegemonía o corresponsabilidad?, Tercer Mundo Editores Colciencias, Bogotá, Colombia.

et al. (2013), Minería en Colombia. Fundamentos para superar el modelo extractivista, Contraloría General de la República de Colombia, Bogotá. González, Roberto (2015), “Boquete de \$124 mil millones al gasto”, La Jornada, <http://www.jornada.unam.mx/2015/01/31/politica/002n1pol>

Harvey, David (1990), Los límites del capitalismo y la teoría marxista, México, Fondo de Cultura Económica. (2004), El nuevo imperialismo, Madrid, España, Akal. (2007), Breve historia del Neoliberalismo, Madrid, España, Akal. (2014), Diecisiete contradicciones y el fin del capitalismo, primera ed., Quito, Editorial. 
Instituto de Altos Estudios Nacionales del Ecuador (IAEN) (2014), 296 pp. Juan Mari Madariaga (trad.).

Jalife-Rahme, Alfredo (2014), Bajo la Lupa, La Jornada, <http://www.jornada.unam.mx/2013/12/29/opinion/006o1 pol>

Jessop, Robert (2008), El futuro del Estado capitalista, Catarata, España.

López, Francisco (2014a), Acumulación por desposesión y autonomía indígena, $<$ http://www.lopezbarcenas.org/doc/acumulaci\%C3\%B3n-desposesi\%C3-\%B3n-autonom\%C3\%ADa-ind\%C3\%ADgena>

(2014b), "La segunda desamortización de las tierras", La Jornada, <http://www.jornada.unam.mx/2014/07/25/opinion/019a2pol>

Merchand, Marco (2012), Acumulación por desposesión en la geografía local, Universidad de Guadalajara.

McKinsey Global Institute (2014), A Tale of Two Mexicos: Growth and Prosperity in a Two-speed Economy, McKinsey Global Institute, <http://www. mckinsey.com/insights/americas/a_tale_of_two_mexicos>

Miliband, Ralph (1978), Marxismo y politica, España, Siglo XXI Editores.

Nadal, Alejandro (2013), "Crisis económica y crisis del Estado", La Jornada, <http://www.jornada.unam.mx/2013/12/18/economia/030a1eco>

Petrich, Blanche (2014a), "24 Cumbre Iberoamericana. Cepal insta a México a imitar modelos energéticos de Bolivia y Ecuador", La Jornada, <http:// www.jornada.unam.mx/2014/12/09/politica/004n1pol>

(2014b), "Ningún país debe dejar sus energéticos en manos extranjeras: Álvaro García Linera", La Jornada, <http://www.jornada.unam.mx /2014/12/22/politica/012n1pol>

Robinson, William (2013), Una teoría sobre el capitalismo global: producción, clase y Estado en un mundo transnacional, México, Siglo XXI Editores.

TPP (2014), Libre comercio, violencia, impunidad y derechos de los pueblos en México. Audiencia final, <http://www.internacionaleliobasseit, http:// issuu.com/tppmexico/docs/sentencia_audiencia_final_tpp_mexic>

Seoane, José (2012), "Neoliberalismo y ofensiva extractivista. Actualidad de la acumulación por despojo, desafíos de nuestra América", Theomai 26, segundo semestre, Buenos Aires, Argentina.

Saxe, John (2002), La compra y venta de México, México, Plaza y Janés.

Zenteno Lira Mora (2014), Reforma Energética Resumen del proyecto de decreto que expide las leyes secundarias en materia de hidrocarburos, $<$ http://www.pwc.com/es_MX/mx/industrias/archivo/2014-05-secundarias-hidrocarburos.pdf>

Wallerstein, Immanuel (1988), El capitalismo histórico, México, Siglo XXI Editores. 
